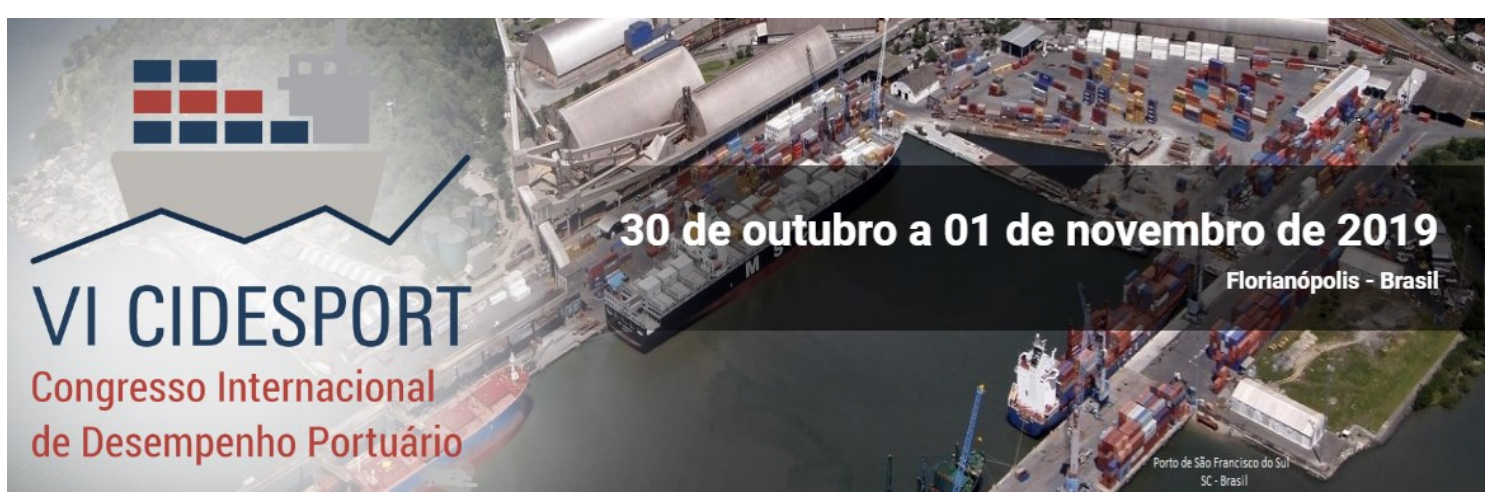

\title{
PROGRAMA DE VISITAS COMO FORMA DE APROXIMAÇÃO PORTO-CIDADE NO PORTO DE IMBITUBA
}

\section{Géssica da Silva \\ SCPar Porto de Imbituba}

\section{Amanda Cristhie Trummer Gomes \\ SCPar Porto de Imbituba}

Resumo: Em 2012, a administração do Porto de Imbituba foi concedida ao Estado de Santa Catarina. Até então, o Complexo Portuário foi administrado e estruturado por uma empresa privada, que o geriu por 70 anos. A troca de gestão causou uma ruptura no relacionamento da Autoridade Portuária com a comunidade local, seja pela troca do corpo funcional por trabalhadores concursados ou pelo crescente controle de segurança e acesso ao Porto, causando o distanciamento da gestão no dia a dia da cidade. Para reverter este cenário, a SCPar Porto de Imbituba tem colocado em prática algumas estratégias com fins de aproximação Porto-Cidade. Entre elas está a criação do Programa de Visitas Porto de Portas Abertas, implantado em 2016 com o objetivo de viabilizar a visitação de instituições de ensino fundamental e médio, técnico e superior. Desde então, o programa tem se consolidado e recebido, em média, 900 pessoas por ano, distribuídas em aproximadamente 34 visitas anuais. Após dois anos de atuação, identificou-se que a procura por visitas das instituições de ensino de Imbituba era praticamente nula, ao mesmo tempo em que era frequente o pedido de cidadãos locais para conhecerem as operações portuárias in loco. Nesse contexto, a administração portuária promoveu ações em duas frentes, para aumentar a visitação de (1) estudantes e de (2) moradores de Imbituba ao Porto. Desde 2018, as ações vêm despertando cada vez mais o interesse de escolas e da sociedade local em conhecerem o Porto e, a cada nova visita, promovem a aproximação com a comunidade de forma direta, no que tange à construção de relacionamento, transparência na gestão e compartilhamento de informações.

Palavras-chaves: Porto. Programa de visitas. Porto-cidade. Porto de imbituba

\section{INTRODUÇÃo}

Localizado em ponto estratégico no sul do Brasil, o Porto de Imbituba é privilegiado pelo acesso imediato ao mar aberto. Suas águas calmas, protegidas por um molhe de 850 metros, permitem manobras de atracação e desatracação rápidas e seguras. Possui três berços de atracação e é considerado o Porto mais profundo entre os Portos públicos da Região Sul do Brasil, com profundidade de 15 metros nos berços 1 e 2. O Porto está conectado aos principais centros produtores do Brasil por meio dos modais rodoviário, ferroviário e aeroportuário. O acesso pela BR-101 está distante apenas $6 \mathrm{~km}$ do Complexo Portuário, o qual também é atendido pela malha da Ferrovia Tereza Cristina (FTC), que liga o Porto ao município de Criciúma (SC). No

\footnotetext{
* A revisão gramatical, ortográfica, ABNT ou APA foi realizada pelos autores.
} 


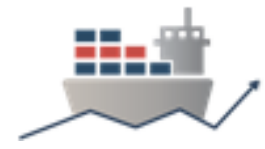

Porto de Imbituba, predominam as movimentações do complexo de grãos (soja e milho) e de coque de petróleo, além de volumes de contêineres, sal, madeiras, fertilizantes, soda cáustica, entre outros. O Porto possui uma área terrestre de mais de 1 milhão de $\mathrm{m}^{2}$, estruturada com 5 terminais para armazenagem e movimentação de todos os tipos de cargas: granéis sólidos e líquidos, contêineres e cargas gerais.

O Porto de Imbituba foi idealizado na década de 1880 para atender as demandas de escoamento do carvão descoberto no sul catarinense no início do século. Nascia naquele período o complexo carbonífero catarinense, composto pelo tripé minaferrovia-Porto (minas de carvão da cabeceira do Rio Tubarão; a Ferrovia Tereza Cristina, inaugurada em 1884 e os Portos de Imbituba e Laguna). O tripé que inicialmente foi idealizado e seria construído por Visconde de Barbacena, em associação com uma companhia inglesa, logo foi abandonado tanto pela baixa qualidade do mineral, quanto pela grande necessidade de investimentos em infraestrutura. Para o Porto de Imbituba, a herança desta época foi um trapiche construído pelos ingleses. O terreno onde se localizava o Porto foi adquirido em 1887 pela firma Lage \& Irmãos, famoso conglomerado empreendedor que tinha como sede o Rio de Janeiro, e detinha negócios nas áreas de mineração, energia elétrica, navegação marítima e aérea, construção civil, entre outros. O efetivo aparelhamento do Porto passou a ser concretizado a partir de 1919, por iniciativa própria dos Lage. Em 1922 a empresa funda a Companhia Docas de Imbituba para dar continuidade ao projeto de exploração do Porto. No entanto, apenas em 1941, através do Decreto Federal $n^{\circ} 7.842$ de 13/09/1941, chega a concessão para a construção, aparelhamento e exploração do Porto de Imbituba, por um período de 70 anos (BOSSLE, 1979; COLONETTI, GOULARTI FILHO, 2014; GOULARTI FILHO, 2010). Com o término da concessão, em 2012, o Porto de Imbituba foi então delegado ao Governo do Estado de Santa Catarina, o qual obteve autorização de exploração concedida em 26 de novembro de 2012. Nesse contexto, nasce a SCPar Porto de Imbituba, empresa pública catarinense subsidiária de propósito específico, da holding SC Participações e Parcerias, para exercer a Autoridade Portuária de Imbituba (PORTO DE IMBITUBA, 2018).

A partir da assunção do Porto pelo governo catarinense, um extenso campo de oportunidades de desenvolvimento regional pôde ser observado. A operação portuária cresceu $154 \%$ no volume de cargas movimentadas no acumulado de 2012 a 2018 e novos produtos passaram a ser embarcados. $O$ próprio cenário retroportuário modificou grandemente no período, com a reestruturação da rodovia de acesso ao Porto e a construção de diversos armazéns pela iniciativa privada (PORTO DE IMBITUBA, 2018).

A política de gestão com foco no crescimento sustentável, na legalidade, na transparência e no diálogo, além do desempenho operacional positivo e da crescente estruturação para a eficiência do Complexo Portuário têm sido reconhecidos por renomadas instituições, as quais conferiram à Autoridade Portuária diversos prêmios socioambientais nos últimos anos.

A Secretaria Nacional de Portos destaca a importância da "Relação PortoCidade", sustentando o desenvolvimento do setor portuário a partir de parcerias capazes de promover sua modernização, sem abandonar os princípios da sustentabilidade e sem perder de vista o interesse público. Presente há mais de um século na vida de Imbituba, a representatividade da atividade portuária no município, tanto nos aspectos econômicos, quanto culturais e sociais, integra a identidade dos imbitubenses. Fatores como a longa inserção da família Lage no desenvolvimento não apenas do Porto, como também da cidade; a era pós ISPS Code, que exigiu a adoção 
de políticas internacionais de segurança e maior rigor e controle no acesso ao Porto; e a estatização administrativa certamente contribuíram para um natural afastamento relacional do Porto com a cidade. Neste sentido, iniciativas como programas de visitação são uma alternativa que a Autoridade Portuária do Complexo Portuário de Imbituba tem realizado para não só apresentar o Porto de Imbituba, mas especialmente interagir com a comunidade local.

\section{CONTEXTO}

As histórias do Porto e da cidade de Imbituba se fundem umbilicalmente. A região no século XIX era uma vila de pescadores com quase nenhuma estrutura. A chegada da família Lage na região traz um planejamento urbano para a localidade, especialmente para atender aos planos de crescimento do complexo portuário e às necessidades dos trabalhadores. Nesse sentido, destaca-se a construção da Vila Operária, com residências no entorno portuário para os funcionários do alto escalão da empresa, o projeto e construção da Usina Termoelétrica e da Caixa d'água, que abasteciam o Porto, um hotel, a vila operária e as principais estruturas da família Lage, assim como a criação da Granja Henrique Lage, para o abastecimento hortifrutigranjeiro da localidade. Além das obras de infraestrutura, enfatiza-se o protagonismo de Henrique Lage na construção social de Imbituba, como a construção do prédio do Grupo Escolar, que deu origem à primeira escola e primeira rádio da cidade. $\mathrm{O}$ comércio local acontecia dentro da própria estrutura portuária. $\mathrm{O}$ prédio chamado de "cooperativa", localizado ao lado do escritório da Administração, ofertava aos funcionários gêneros alimentícios, além de itens de cama, mesa e banho, entre outras mercadorias, para serem anotados em sua ficha funcional e descontados do pagamento (SANTANNA, 2016). Santanna (2016) descreve que não era raro um pai de família com muitos filhos trabalhar sem receber nada ao fim do mês, visto que seus débitos somavam mais que seu provento.

Ao analisar as fotos aéreas do complexo portuário antes do seu cercamento, é possível perceber a total integração do Porto com a cidade de Imbituba (Imagem 1). O Porto de Imbituba, conhecido durante quase todo o século XX como um Porto carvoeiro, tinha espaços destinados ao armazenamento de carvão por toda sua área. A circulação de pessoas era livre e o Porto nunca foi somente o local de trabalho dessa população. A Capela de São Pedro, ou Capelinha da Praia, fundada em 1898, funcionou como principal local religioso do centro da cidade até a inauguração da Igreja Matriz, em 1954. Muitas foram as festividades que ocorreram dentro do área do Porto. O primeiro cinema de Imbituba funcionou num armazém portuário, com ingressos impressos na própria tipografia da Companhia Docas de Imbituba (SANTANNA, 2016). 


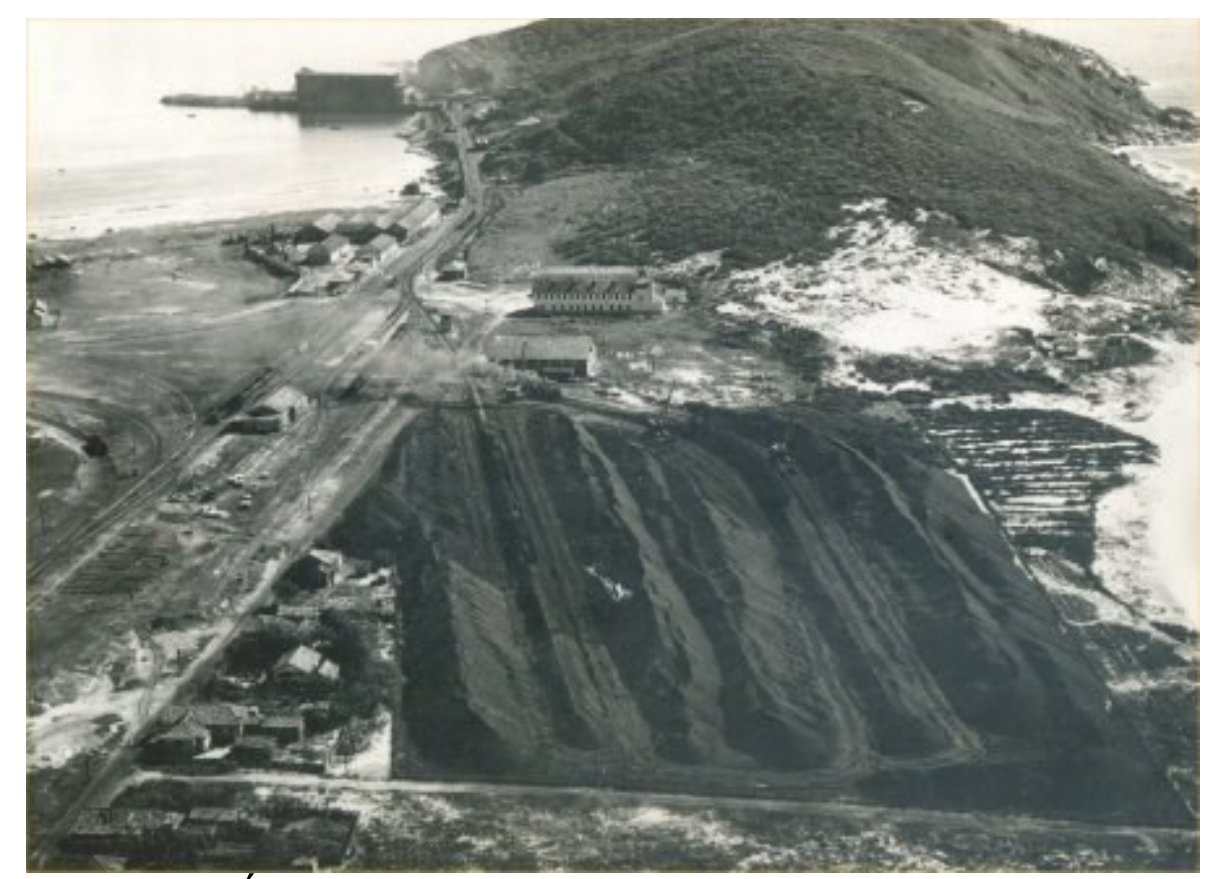

Imagem 1: Área portuária - Acervo CDI

Após os atentados de 11 de setembro nos EUA, as áreas portuárias e aeroportuárias tiveram de passar por adaptações em seus sistemas de segurança. Em 2004, entrou em vigor o ISPS Code, Código Internacional para Segurança de Navios e Instalações Portuárias, que é uma norma internacional de segurança para controle de acessos e monitoramento. No Brasil, as inspeções dos terminais e as concessões dos certificados são de responsabilidade da ConPortos (Comissão Nacional de Segurança Pública nos Portos, Terminais e Vias Navegáveis), seguindo o código internacional passado pela Organização Marítima Internacional (IMO). O Porto de Imbituba fechou seu perímetro em 2004, no início das adaptações necessárias para obtenção do Certificado de Cumprimento do ISPS Code, fundamental para operar com navios de tráfego marítimo internacional. O certificado foi recebido pela Companhia Docas de Imbituba em 2007 (CDI, 2007).

Em 2012, o fim da concessão da União à Companhia Docas de Imbituba e posterior convênio de delegação ao governo do Estado de Santa Catarina, através da holding SC Participações e Parcerias, põe fim a uma relação centenária de interdependência da cidade e do Porto. Como toda a situação de mudança, a chegada de uma empresa totalmente nova na cidade provocou ruptura no relacionamento Porto-cidade. Foram demitidos os empregados da CDI, e admitidos novos trabalhadores vindos de outras regiões do estado, primeiro através de cargos comissionados e, a partir de 2015, por meio de concurso público. O sentimento geral foi de que o Porto se afastou da comunidade, trouxe desemprego e quebra na cultura local.

\section{INTERVENÇÃO}

Desde que estabeleceu seus conceitos estratégicos para gestão do Porto, a SCPar Porto de Imbituba instituiu a "integração com a sociedade e a comunidade portuária" como um de seus Valores. Em 2016, aproximadamente um ano após a admissão do corpo técnico concursado, a empresa passou a ter capacidade de equipe para explorar ações de aproximação Porto-Cidade, dentro dos limites das normativas 


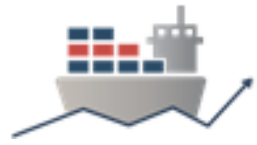

estabelecidas no seu convênio de delegação. Do interesse manifesto em ofícios recebidos pela Autoridade Portuária, principalmente de instituições de ensino técnico e superior, nasceu o Programa Porto de Portas Abertas. O programa viabiliza visitas institucionais, agregando conhecimento prático e teórico sobre as operações portuárias, e apresenta as ações sociais e ambientais promovidas pela SCPar. O objetivo inicial era atender a demanda latente e viabilizar visitas institucionais para alunos do ensino fundamental e médio, além de estudantes de cursos técnicos e universitários.

O agendamento da visitação era uma ação reativa, atendida conforme a demanda e sem grandes divulgações para atração de novos visitantes. O roteiro básico de visitação que vem sendo executado até hoje inclui uma apresentação inicial do Porto, para transmitir informações sobre o cenário portuário brasileiro; a história, características de infraestrutura e operações do Porto de Imbituba; os índices de movimentação portuária e os programas de gestão social e ambiental. O itinerário é seguido de uma visita à área alfandegada, onde os visitantes podem vivenciar in loco o funcionamento do Porto, passando pelos terminais até o cais, onde os estudantes descem e podem acompanhar a operação de embarque/desembarque de cargas nos navios. Com a finalidade de atender melhor às expectativas e áreas de estudo dos diferentes grupos que podem visitar a Autoridade Portuária, as visitas são divididas em diferentes temáticas, apresentadas por um empregado do respectivo setor, chamado posteriormente de Mediador, conforme tabela 1 abaixo:

\begin{tabular}{|l|ll|}
\hline Área de estudo & Mediador \\
\hline Administração e Operação Portuária & Setor de Operações & \\
\hline Gestão ambiental e Marégrafo & $\begin{array}{l}\text { Setor de Saúde, Segurança e Meio } \\
\text { Ambiente }\end{array}$ \\
\hline Infraestrutura e Engenharias & Setor de Obras & \\
\hline Escolas & Setor de Comunicação Social & \\
\hline Autoridades & Setor de Operações ou Setor de \\
\hline
\end{tabular}

Tabela 1: Áreas temáticas das visitas

O Programa de visitas do Porto de Imbituba funcionou desta forma até 2017. No entanto, no período, foi verificada a baixíssima procura de escolas de ensino fundamental e médio de Imbituba para visita ao Porto. Dos 37 grupos de visitantes recebidos naquele ano, foi atendido apenas 1 grupo escolar do município.

Compreendendo o Porto de Imbituba como parte das referências culturais inseridas em um contexto de significados da memória social local, e considerando integração com a sociedade e a comunidade portuária como um Valor da empresa, buscou-se alguma alternativa para atrair a visitação de escolas de ensino fundamental e médio do município de Imbituba. De acordo com o Instituto do Patrimônio Histórico e Artístico Nacional, (IPHAN, 2014, p. 20), "as iniciativas educativas devem ser encaradas como um recurso fundamental para a valorização da diversidade cultural e para o fortalecimento da identidade local, fazendo uso de múltiplas estratégias e situações de aprendizagem (...)". Nesse processo, segundo o Iphan (2014, p. 21), 


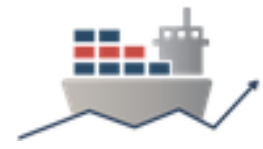

"cabe aos poderes públicos exercer o papel de mediador da sociedade civil, contribuindo para a criação de canais de interlocução que se valem, em especial, de mecanismos de escuta e observação".

Ainda em 2017, no contexto de elaboração interna do Planejamento Estratégico de Longo Prazo, foi inserido um indicador de visitações ao Porto, buscando qualificar e solidificar o Programa Porto de Portas Abertas. No ano seguinte, buscou-se catalogar todas as escolas públicas e privadas do município e foi enviado um ofício apresentando o Programa e convidando a escola a visitar o Porto. O resultado foi imediato, das 26 instituições de ensino fundamental e médio do município, 10 grupos de 6 escolas participaram do Programa em 2018.

No entanto, ainda que estivéssemos pouco a pouco alcançando o objetivo de interação com as instituições de ensino local, ainda faltava uma aproximação mais direta com a comunidade. Eram constantes os pedidos de cidadãos para conhecerem o Porto, seja pela curiosidade, por turismo ou pela ligação que a pessoa já teve com o local. Alguns trabalharam ou tinham familiares que já atuaram no Porto, outros contam que vinham brincar ou pescar no cais. Assim, por iniciativa da Autoridade Portuária, em 2019 foi implantada a ação "Porto de Portas Abertas - Comunidade".

$\mathrm{O}$ convite à comunidade foi feito realizado via redes sociais do Porto de Imbituba (Facebook, Linkedin e Instagram) e através de release enviado à imprensa regional. $\mathrm{Em}$ apenas 10 horas, as 40 vagas disponíveis para a primeira visita haviam sido preenchidas. Em dois dias, a fila de espera ultrapassava 170 pessoas. $O$ convite provocou um sentimento de animosidade na cidade e, apesar do esperado interesse, surpreendeu a Autoridade Portuária pela pronta e volumosa resposta da comunidade.

A princípio, estava prevista apenas uma visita da comunidade por semestre. Todavia, atendendo a grande procura pela visita, ficou decidido zerar a fila de espera e atender mais três grupos da comunidade até dezembro de 2019. Ainda, para 2020, já está confirmada a realização de pelo menos 10 visitas da comunidade no Porto de Imbituba.

\section{RESULTADOS OBTIDOS}

Estabelecer um relacionamento, seja em qualquer âmbito da vida, exige o compartilhar valores como confiança, transparência e diálogo. Na relação PortoCidade não é diferente. As pesquisas acadêmicas na área têm apontado modelos teóricos focados principalmente no desenvolvimento da interface espacial e temporal da relação Porto-Cidade. Estudos mais recentes (DAAMEN, 2007) têm ampliado esta perspectiva e trazem à luz uma interpretação interdisciplinar, envolvendo não apenas suas características espaciais, mas também econômicas, socioculturais e ambientais. Para Monié e Vidal (2006), o processo de construção ou fortalecimento da integração Porto-Cidade, fruto da interação entre os agentes sociais e institucionais, requer a inclusão de elementos históricos, culturais e sociais, já que se trata de uma relação que ainda comporta estigmas, perdas, redefinições de funções, conflitos e interesses diversos.

Ao todo, a administração do Porto de Imbituba recebeu 877 visitantes em 2018, distribuídos em 41 visitas. Quanto às cidades de origem dos participantes, a maioria provém da Região Centro-Sul de Santa Catarina, onde se destacam os municípios de Imbituba (14 visitas); Florianópolis (8 visitas); Criciúma (4 visitas) e Garopaba (4 visitas). De fora do estado, foram registradas visitas de grupos do Rio Grande do Sul; Mato Grosso do Sul e São Paulo. Junho, setembro e outubro foram os meses com maior número de visitantes, concentrando $46,7 \%$ do total anual. 


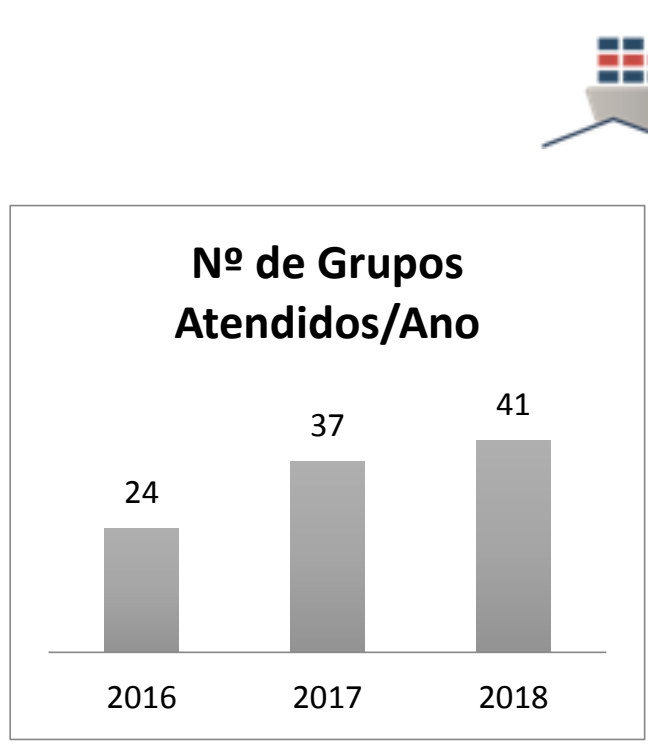

Gráfico 1: № visitantes/ano

Gráfico 2: № de grupos atendidos/ano

Dos grupos atendidos em 2018, 19 eram instituições de ensino técnico e superior e 14 escolas de ensino fundamental. A partir de novembro, a visita de crianças ganhou um enfoque ambiental, com a distribuição do livro infantil A Grande Tempestade, desenvolvido no âmbito do projeto Mar de Letras, da SCPar Porto de Imbituba. Outro fator relacionado ao público infantojuvenil são os trabalhos de sala de aula elaborados nas escolas de Imbituba em função da visita ao Porto, como a construção de maquetes e a escrita de paródias musicais. As maquetes produzidas pelos alunos da Escola Municipal Professora Terezinha Pinho de Souza, após visitação ao complexo portuário, foram expostas aos colaboradores da SCPar Porto de Imbituba na $3^{a}$ SIPAT - Semana Interna de Prevenção de Acidentes de Trabalho.

Em 2018 foi aplicada a Pesquisa de Satisfação dos visitantes. Os resultados compilados apontaram alto índice de satisfação de todos os itens avaliados, desde o processo de agendamento até a possível adequação do conteúdo transmitido ao processo de aprendizado em sala de aula.

Comumente eram recebidos pelo setor de Comunicação Social comentários e pedidos de visitas vindos de cidadãos comuns, que não estavam entre o público-alvo inicialmente contemplado pelo programa Porto de Portas Abertas. Pensando numa forma de receber mais pessoas através das portas do Porto de Imbituba, lançou-se a campanha Porto de Portas Abertas - comunidade, prevista para uma manhã de sábado, a fim de que mais pessoas pudessem participar. O objetivo era primordialmente estreitar os laços com a comunidade, apresentando os trabalhos desenvolvidos internamente na empresa e esclarecendo diversas dúvidas. A grande resposta da comunidade ao primeiro convite para visita acabou afetando positivamente a intervenção realizada. No lugar de 2 visitas anuais, estão sendo realizadas 4 encontros no ano de 2019. Para 2020 o cenário é ainda mais animador, com 10 visitas confirmadas para serem realizadas de fevereiro a novembro, uma vez por mês. Esse contexto demonstra não apenas a continuidade do Programa, como também seu amadurecimento enquanto ferramenta social.

\section{CONCLUSÕES}

É primordial pensar a função social do Porto de Imbituba dentro do município, região e estado. Destacamos a importância de rememorar as transformações que ocorreram no cais do Porto, as mudanças na vida dos trabalhadores e a própria relação do imbitubense com o Porto e o mar, buscando destacar a importância histórica, econômica e social que o Complexo Portuário teve e tem para Imbituba. É 
de fundamental importância para o estabelecimento dessa relação Porto-cidade agir em defesa do patrimônio cultural local como fonte de pesquisa e conhecimento, explorando a inserção do aluno e do cidadão na comunidade da qual ele faz parte, a fim de criar sua identidade e historicidade.

Com essa finalidade, buscaremos fortalecer ainda mais a cultura da visita ao Porto de Imbituba nas escolas do município nos próximos anos. Para 2020 , além da expansão do programa para a comunidade, a proposta é estender o convite aos municípios vizinhos, como Laguna, Tubarão, Garopaba, Imaruí, Paulo Lopes e Pescaria Brava.

Algumas melhorias em termos de avaliação qualitativa do Programa e sistematização do processo de agendamento das visitas também devem ser implantadas em breve, visando não apenas a maior eficiência na sua gestão, como também a promoção de sua eficácia. Esta está fundamentada na proposta de voltar avaliar os feedbacks dos visitantes por meio da Pesquisa de Satisfação. Já a sistematização virá da implantação de uma ferramenta de agendamento online, acelerando o processo de aprovação das visitas e coleta de informações dos visitantes para liberação de acesso ao Porto.

O Programa Porto de Portas Abertas do Porto de Imbituba tem sido não apenas um, entre tantos mecanismos possíveis, de aproximação Porto-Cidade. Ao abrir as portas do Complexo Portuário para as instituições de ensino e a população local, e trazer novamente sua presença para um espaço já tão enraizado em sua cultura, a Administração do Porto ratifica sua função de interesse público, promove aspectos de governança e transparência na gestão e viabiliza o diálogo com a comunidade.

\section{REFERÊNCIAS}

BOSLLE, Ondina Pereira. Henrique Lage e o Desenvolvimento Sul Catarinense. Florianópolis: Ed. UFSC, 1979.

COLONETTI, Ricardo Alves; GOULARTI FILHO, Alcides. Crise e diversificação no Porto de Imbituba: uma análise do período 1990-2012. In: ESTEVAM, Dimas de Oliveira; FABRIS, Thiago Rocha. Ensaios sobre a economia Sul Catarinense. V. III. Criciúma: UNESC, 2017.

COMPANHIA DOCAS DE IMBITUBA. Declaração de Cumprimento $n^{0}$ 154/2007. Disponível em: https://www.cdiport.com.br/images/isps/certificado.jpg. Acesso em 15 abri 2019.

DAAMEN, T. Sustainable development of the european port-city interface. In: International Conference on Sustainable Urban Areas, Rotterdam. Anais ENHR Conference, 2007. Disponível em:

https://www.researchgate.net/publication/228798104_Sustainable_development_of_t he_European_port-city_interface/download. Acesso em 15 abri 2019.

GOULARTI FILHO, Alcides. O Porto de Imbituba na formação do complexo carbonífero catarinense. Revista de História Regional. Ponta Grossa, PR, v. 15, n. 2, p. 235-263, inverno 2010. Disponível em: < http://www.revistas2.uepg.br/index.php/rhr/article/view/2379> 
VI CIDESPORT/2019

Congresso Internacional

de Desempenho Portuário

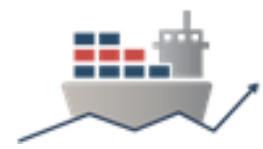

IPHAN. Educação Patrimonial: histórico, conceitos e processos. Brasília: Instituto do Patrimônio Histórico e Artístico Nacional, 2014.

MONIE, Frédéric; VIDAL, Soraia Maria do S. C.. Cidades, portos e cidades portuárias na era da integração produtiva. Rev. Adm. Pública, Rio de Janeiro, v. 40, n. 6, p. 975-995, Dez. 2006.2 Disponível em: http://www.scielo.br/scielo.php?script=sci_arttext\&pid=S0034-

$76122006000600003 \&$ Ing=en\&nrm=iso. Acesso em 9fev 2019.

PORTO DE IMBITUBA. Porto de Imbituba: na rota da modernidade. Palhoça: Editora Unisul, 2018.

SANTANNA, Maria Aparecida Pamato. Imbituba nas conjunturas do tempo. Imbituba: Livropostal, 2016. 